\title{
Guggulsterone inhibits human cholangiocarcinoma Sk-ChA-1 and Mz-ChA-1 cell growth by inducing caspase-dependent apoptosis and downregulation of survivin and Bcl-2 expression
}

\author{
FEI ZHONG ${ }^{1 *}$, JING YANG ${ }^{2 *}$, ZHU-TING TONG ${ }^{3}$, LIU-LIU CHEN ${ }^{1}$, \\ LU-LU FAN $^{1}$, FANG WANG ${ }^{1}$, XIA-LI ZHA ${ }^{1}$ and JUN LI ${ }^{1}$ \\ ${ }^{1}$ Department of Oncology, The First Affiliated Hospital of Anhui Medical University, Hefei, Anhui 230022; \\ ${ }^{2}$ Department of Neurology, Anhui Provincial Hospital, Hefei, Anhui 230001; \\ ${ }^{3}$ Department of Radiation Oncology, The First Affiliated Hospital of Anhui Medical University, \\ Hefei, Anhui 230022, P.R. China
}

Received July 9, 2014; Accepted May 27, 2015

DOI: $10.3892 / 01.2015 .3391$

\begin{abstract}
Guggulsterone has recently been reported to demonstrate anti-tumor effects in a variety of cancers. The present study aims to investigate the biological roles and underlying mechanism of the action of guggulsterone in cholangiocarcinoma. The immortalized human cholangiocarcinoma Sk-ChA-1 and Mz-ChA-1 cell lines were treated with various concentrations of the trans isomer of guggulsterone, Z-guggulsterone. Cellular proliferation was determined using the XTT assay. The apoptotic status of cholangiocarcinoma cells was assessed by Hoechst 33258 staining, DNA fragmentation assay and flow cytometry. Specific caspase inhibitor was used to explore the role of caspase in guggulsterone-induced apoptosis. A colorimetric assay was performed to measure the alterations of the activities of caspase- $3,-8$ and -9 . Western blot analysis was used to detect the protein expression of survivin, B-cell lymphoma 2 (Bcl-2), Bcl-2-associated $\mathrm{X}$ protein and cleaved poly (adenosine diphosphate-ribose) polymerase (PARP). As revealed by the present data, guggulsterone significantly inhibited the growth of the two human cholangiocarcinoma cell lines by inducing cellular apoptosis. In addition, guggulsterone-induced apoptosis of cholangiocarcinoma cells was demonstrated to be partially inhibited by the caspase inhibitors z-VAD-fmk, z-LEHD-fmk and z-IETD-fmk, accompanied by the activation of caspases-3, -8 and -9 , accumulation of cleaved PARP and decreased expression of survivin and
\end{abstract}

Correspondence to: Professor Jun Li, Department of Oncology, The First Affiliated Hospital of Anhui Medical University, 218 Ji Xi Road, Hefei, Anhui 230022, P.R. China

E-mail: 18226616729@163.com

${ }^{*}$ Contributed equally

Key words: guggulsterone, cholangiocarcinoma, apoptosis, caspase, Survivin, B-cell lymphoma 2
Bcl-2. In conclusion, the present study demonstrated that guggulsterone was able to suppress the proliferation of cholangiocarcinoma by inducing caspase-dependent apoptosis and downregulating survivin and Bcl-2.

\section{Introduction}

Cholangiocarcinoma is a malignancy that arises from the neoplastic transformation of cholangiocytes, and currently, this disease accounts for between 10 and $15 \%$ of all hepatobiliary tumors and the incidence is rising globally $(1,2)$. Despite previous advances in illustrating the molecular characteristics of cholangiocarcinoma, the treatment remains challenging, and there has been no significant change in the overall five-year survival rate of patients over previous decades $(3,4)$. Therefore, exploration of the molecular events underlying the initiation and progression of cholangiocarcinoma is urgently required.

Apoptosis, also termed programmed cell death, plays an important role in controlling cellular proliferation as part of normal development (5). Numerous previous studies have revealed that downregulated apoptotic pathways contribute to chemoresistance in cancer cells, and enhanced apoptosis is a key mechanism by which chemotherapeutic agents exert their antitumor effects $(6,7)$. Thus, the induction of apoptosis is currently considered to be an index for selecting novel anticancer drugs $(7,8)$.

Guggulsterone is a polyphenol that is derived from Commiphora mukul, a plant native to India. For thousands of years, guggulsterone has been used to treat various human diseases, including inflammation, arthritis and cardiovascular disease (9-11). The active components of this herbal extract are the trans Z- and cis E-isomers of guggulsterone (12).

Previous studies have reported that guggulsterone possesses anticancer potential due to the anti-proliferative and apoptosis-inducing effects exerted by this agent on a panel of human cancers, including leukemia, breast carcinoma, prostate cancer, colorectal cancer, pancreatic carcinoma and esophageal cancer (13-18). 
However, to the best of our knowledge, the effect of guggulsterone on human cholangiocarcinoma remains to be elucidated. In the present study, the effects of guggulsterone on cellular proliferation and apoptosis in cholangiocarcinoma Sk-ChA-1 and Mz-ChA-1 cells were explored, and the underlying mechanism was investigated.

\section{Materials and methods}

Reagents. Z-guggulsterone (Fig.1) was purchased from Sigma-Aldrich (St. Louis, MO, USA). The stock solution was prepared in dimethyl sulfoxide (DMSO; Solar Biotechnology, Inc., Shanghai, China) and then diluted with serum-free medium. RPMI-1640 and heat-inactivated fetal calf serum were obtained from Gibco Industries (Tulsa, OK, USA). The XTT proliferation kit and Hoechst 33258 were purchased from Boehringer Ingelheim (Mannheim, Germany). The Caspase Activity Colorimetric Assay kit, pan-caspase inhibitor z-VAD-fmk, capase- 8 inhibitor z-IETD-fmk and caspase-9 inhibitor z-LEHD-fmk were purchased from Assay Designs (Ann Arbor, MI, USA). The following primary antibodies were also used: Rabbit anti-cleaved poly (adenosine diphosphate-ribose) polymerase (PARP; cat no. G3411; Promega, Madison, WI, USA); mouse anti-human survivin (cat no. sc-65610; 1:300 dilution; Santa Cruz Biotechnology, Inc., Dallas, TX, USA); mouse anti-human B-cell lymphoma 2 (Bcl-2; cat no. sc-377576; 1:500 dilution; Santa Cruz Biotechnology, Inc.); and goat anti-human Bcl-2-associated X protein (cat no. sc-20287; 1:1,100 dilution; Santa Cruz Biotechnology, Inc.). The rabbit anti-mouse (cat no. sc-358961; 1:1,000 dilution), bovine anti-rabbit (cat no. sc-362290; 1:1,000 dilution) and bovine anti-goat (cat no. sc-362284; 1:1,000 dilution) secondary antibodies were all obtained from Santa Cruz Biotechnology, Inc. The present study was approved by the ethics committee of Anhui Medical University (Hefei, China).

Cell lines culture. The human immortalized cholangiocarcinoma Sk-ChA-1 and Mz-ChA-1 cell lines were purchased from the Cell Bank of Type Culture Collection of Chinese Academy of Sciences (Shanghai, China). The cells were routinely cultured in RPMI-1640 supplemented with $10 \%$ heat-inactivated fetal calf serum, $2 \mathrm{mmol} / \mathrm{l} \mathrm{L}$-glutamine and $5 \mathrm{U} / \mathrm{ml}$ penicillin (Solar Biotechnology, Inc.)in a humidified incubator with a 5\% $\mathrm{CO}_{2}$ atmosphere at $37^{\circ} \mathrm{C}$.

Cell viability assay. The effects of guggulsterone on the viability of Sk-ChA-1 and Mz-ChA-1 cells were determined by the XTT assay. In brief, $1 \times 10^{4}$ cells/well were seeded into a 96-well plate and incubated for $24 \mathrm{~h}$, and these cells were then treated with 0 , 20, 40 and $60 \mu \mathrm{mol} / 1 \mathrm{Z}$-guggulsterone. Cells treated with only DMSO were used as the control. At the indicated time points, $50 \mu \mathrm{l}$ of XTT/phenazine methosulfate (PMS) mixture (Solar Biotechnology, Inc.), consisting of $50 \mu \mathrm{mol} / 1 \mathrm{PMS}$ and $0.1 \%$ XTT in medium, was added to the cell culture media and incubated continuously for 4 hours. The absorbance at $450 \mathrm{~nm}$ was then measured using a Synergy ${ }^{\mathrm{TM}}$ HT multi-mode microplate reader (Bio-Tek Instruments, Inc., Winooski, VT, USA).

Hoechst 33258 staining. The cholangiocarcinoma cells were seeded into a six-well plate and routinely cultured overnight in
RPMI-1640 medium containing 10\% fetal calf serum. These cells were then treated with $60 \mu \mathrm{mol} / 1 \mathrm{Z}$-guggulsterone for $72 \mathrm{~h}$. Subsequently, the cells were fixed with $4 \%$ formaldehyde for $15 \mathrm{~min}$ at room temperature. The cells were then washed twice with $1 \mathrm{X}$ phosphate-buffered saline (PBS) and stained with $10 \mathrm{mg} / \mathrm{l}$ Hoechst 33258 for $1 \mathrm{~h}$ at room temperature. Finally, the alterations in nuclear morphology were observed under fluorescence microscopy (Nikon TE 2000-U; Nikon, Tokyo, Japan).

DNA fragmentation assay. In total, $1 \times 10^{6}$ cells were harvested and washed once in $1 \mathrm{X} \mathrm{Ca}_{2}{ }^{+}$- and $\mathrm{Mg}_{2}{ }^{+}$-free PBS. The cells were then suspended in $400 \mu 1$ cell lysis buffer consisting of 10 mM Tris-HCl (pH 7.4; Solar Biotechnology, Inc.), 10 mM EDTA (pH 8.0) and 0.5\% Triton X-100 (Solar Biotechnology, Inc.). The suspension was incubated at $4^{\circ} \mathrm{C}$ for $15 \mathrm{~min}$. Following centrifugation of the cell lysates at 15,000 x $\mathrm{g}$ for $20 \mathrm{~min}$, the supernatants were collected and incubated with $40 \mu \mathrm{g} / \mathrm{ml}$ proteinase $\mathrm{K}$ and $40 \mu \mathrm{g} / \mathrm{ml}$ RNase A (SBS Genetech Co., Beijing, China) at $37^{\circ} \mathrm{C}$ for $3 \mathrm{~h}$. The lysate was isolated using $0.5 \mathrm{M} \mathrm{NaCl}$ and $50 \%$ 2-propanol and incubated at $-20^{\circ} \mathrm{C}$ overnight. Subsequent to centrifugation at $15000 \mathrm{x} \mathrm{g}$ for $20 \mathrm{~min}$, the pellets were suspended in Tris-EDTA buffer consisting of $10 \mathrm{mM}$ Tris- $\mathrm{HCl}(\mathrm{pH} \mathrm{7.4)}$ and $1 \mathrm{mM}$ EDTA (pH 8.0). The genomic DNA was separated using a $2 \%$ agarose gel and stained with $0.1 \mu \mathrm{g} / \mathrm{ml}$ ethidium bromide (19).

Flow cytometry. Flow cytometry analysis was performed as previously described (18). In brief, the cells treated with Z-guggulsterone or DMSO were harvested and fixed with $75 \%$ ethanol at $-20^{\circ} \mathrm{C}$. Subsequent to washing twice with cold PBS, the fixed cells were then suspended in $100 \mu \mathrm{l}$ RNase A solution $(1 \mathrm{mg} / \mathrm{ml})$ and incubated at $37^{\circ} \mathrm{C}$ for $1 \mathrm{~h}$. Next, $400 \mu \mathrm{l}$ propidium iodide solution $(50 \mu \mathrm{g} / \mathrm{ml})$ was added to the cells, and the cells were subsequently incubated for $30 \mathrm{~min}$ in the dark. Following incubation, the apoptotic status of these cells was measured using a FACScan flow cytometer (Becton-Dickinson, Franklin Lakes, NJ, USA). The data were further analyzed using CellQuest Software (Becton-Dickinson). In the caspase inhibitor assay, the cells were treated with $60 \mu \mathrm{mol} / 1$ Z-guggulsterone for $72 \mathrm{~h}$, with or without 2-h pre-treatment in $100 \mu \mathrm{M}$ of the specific caspase inhibitors. Cellular apoptosis was then measured as aforementioned.

Caspase activity assay. The activity of caspases-3, -8 and -9 was determined using the colorimetric assay kit, according to the manufacturer's instructions. In brief, the cells were lysed in buffer containing 5 mM DTT (Solar Biotechnology, Inc.), $10 \mu \mathrm{g} / \mathrm{ml}$ aprotinin (Santa Cruz Biotechnology, Inc.), $20 \mathrm{mM}$ EDTA (Solar Biotechnology, Inc.), $50 \mathrm{mM}$ HEPES (SBS Genetech Co.), 0.2\% Triton X-100 (Santa Cruz Biotechnology, Inc.), $150 \mathrm{mM} \mathrm{NaCl}$ and $1 \mathrm{mM}$ phenylmethylsulfonyl fluoride (Santa Cruz Biotechnology, Inc.) at $4{ }^{\circ} \mathrm{C}$ for $10 \mathrm{~min}$. Following centrifugation at $10,000 \mathrm{x} \mathrm{g}$ for $10 \mathrm{~min}$ at $4^{\circ} \mathrm{C}$, the supernatant was collected and the protein concentration was measured. Subsequently, $100 \mu \mathrm{g}$ protein was incubated with 0.2 mM DEVD-pNA, IETD-pNAu or LEHD-pNA (Santa Cruz Biotechnology, Inc.), which are substrates of caspases-3, -8 and -9 , respectively. The caspase activity was determined from the absorbance at $405 \mathrm{~nm}$ using the microplate reader. 
Western blot analysis. Total protein was extracted using the RIPA lysis buffer containing protease inhibitors. Equal amounts of protein $(20-50 \mu \mathrm{g})$ were then loaded and separated by $12 \%$ SDS-PAGE and transferred onto the nitrocellulose membranes. For the blocking procedure, the membranes were incubated in 5\% non-fat milk for $1 \mathrm{~h}$. Appropriate primary antibodies were added to the membrane and the membrane was then incubated at room temperature for $2 \mathrm{~h}$. Next, the membranes were incubated with the appropriate secondary antibodies for $2 \mathrm{~h}$ at room temperature. The specific protein bands were then developed using a commercial enhanced P1701 chemiluminescence kit (Applygen Technologies Inc., Beijing, China). The staining density was measured using the GS-710 Imaging Densitometer, which was obtained from Bio-Rad Laboratories (Hercules, CA, USA).

Statistical analysis. All experiments were performed in triplicate and repeated at least three times. The data were expressed as the mean \pm standard deviation. Student's $t$-test was used to determine the significance of the differences between groups. SPSS software (version 15.0; SPSS, Inc., Chicago, IL, USA) was used to perform all statistical analyses and $\mathrm{P}<0.01$ was considered to indicate a statistically significant difference.

\section{Results}

Z-guggulsterone suppressed the proliferation of cholangiocarcinoma cells by enhancing cellular apoptosis. To investigate the cytotoxicity of guggulsterone on cholangiocarcinoma cells, the Sk-ChA-1 and Mz-ChA-1 cells were incubated with Z-guggulsterone for 24, 48 and $72 \mathrm{~h}$. As demonstrated by the present data, treatment with Z-guggulsterone resulted in significant growth suppression of the two cell lines in a dose- and time-dependent manner ( $\mathrm{P}<0.001$ vs. control; Fig. 2). In addition, the Mz-ChA-1 and Sk-ChA-1 cells were sensitive to treatment with $\mathrm{Z}$-guggulsterone. In the group of cells treated with $60 \mu \mathrm{mol} / \mathrm{l} \mathrm{Z}$-guggulsterone for $72 \mathrm{~h}$, the cell viability of Sk-ChA-1 and Mz-ChA-1 cells was 18.78 and $26.98 \%$, respectively.

Hoechst 33258 staining and DNA fragmentation analysis were then performed to investigate whether cytotoxicity induced by guggulsterone resulted from cellular apoptosis. According to the results of Hoechst staining, 72-h treatment with Z-guggulsterone led to notable morphological alterations, such as chromatin condensation and nuclear fragmentation, which were observed in each of the two cholangiocarcinoma cell lines (Fig. 3A). In the agarose gel electrophoresis, a DNA fragment ladder was detected subsequent to 48 -h treatment with guggulsterone, which was more notable subsequent to 72 -h treatment in each of the two cell lines (Fig. 3B). These findings indicated that that guggulsterone may lead to the death of cholangiocarcinoma cells by inducing cellular apoptosis. In addition, flow cytometry was performed to quantify the apoptosis induced by guggulsterone. As revealed in Fig. 3C, there was a significant dose- and time-dependent increase in the proportion of Sk-ChA-1 and Mz-ChA-1 cells in the sub-G1 phase subsequent to treatment with $\geq 20 \mu \mathrm{mol} / 1 \mathrm{Z}$-guggulsterone $(\mathrm{P}<0.001$ vs. control). In addition to the increase of cell growth suppression, cellular apoptosis was also upregulated gradually and the sub-G1 population of the two cells was $>50 \%$ when the cells were treated with $60 \mu \mathrm{mol} / 1 \mathrm{Z}$-guggulsterone for $72 \mathrm{~h}$.

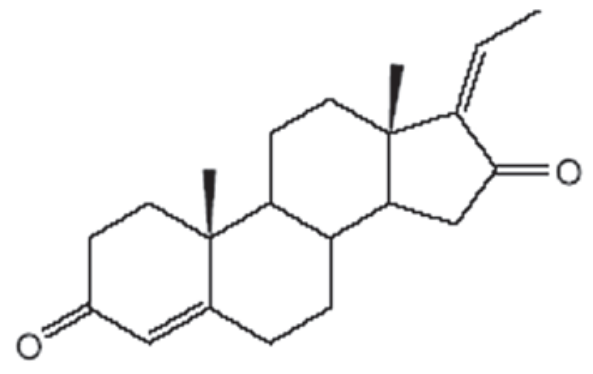

4, 17 (20)-(Trans)-Pregnadien-3, 16-dione

Figure 1. Structure of z-guggulsterone.

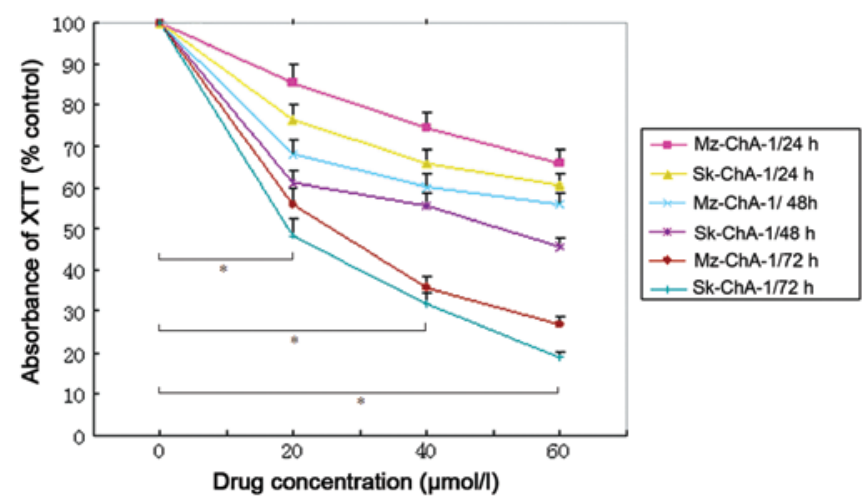

Figure 2. Cell viability subsequent to treatment with guggulsterone. Following treatment of the Sk-ChA-1 and Mz-ChA-1 cells with various concentrations of Z-guggulsterone for 24,48 and $72 \mathrm{~h}$, the number of metabolically active cells was determined using a XTT assay. "P $<0.001$ vs. control. The data were expressed as the mean \pm standard deviation of three replicate experiments.

Involvement of caspases in apoptosis induced by Z-guggulsterone. Considering that caspases play critical roles in cellular apoptosis, the effects of caspase inhibition on Z-guggulsterone-induced apoptosis were then explored. Three caspase inhibitors, consisting of pan-caspase, caspase- 8 and caspase-9 inhibitors, were used in the present study. As shown in Fig. 4A, these inhibitors significantly impaired the apoptosis induced by Z-guggulsterone in Sk-ChA-1 $(\mathrm{P}<0.01)$ and Mz-ChA-1 $(\mathrm{P}<0.001)$ cells, compared with the cells treated with Z-guggulsterone.

The activity of caspases-3, -8 and -9 following treatment with $60 \mu \mathrm{mol} / \mathrm{l} \mathrm{Z}$-guggulsterone was then assessed using colorimetric assay kits. In the Sk-ChA-1 and Mz-ChA-1 cell lines, the highest activity of caspases- 8 and -9 was detected at subsequent to treatment for $48 \mathrm{~h}$, which was followed by a further enhancement of caspase-3 activity subsequent to $72 \mathrm{~h}$ of treatment (Fig. 4B). In addition, the level of cleaved PARP, a hallmark of apoptosis, significantly increased following treatment with $60 \mu \mathrm{mol} / \mathrm{l} \mathrm{Z}$-guggulsterone in a time-dependent manner (Fig. 4C). Overall, the present findings indicated that guggulsterone may induce cytotoxicity in cholangiocarcinoma cells through caspase-dependent apoptosis.

Guggulsterone regulates apoptosis-associated genes. According to the results of western blot analysis, the protein levels of survivin and Bcl-2 were markedly downregulated in a time-dependent manner, while the expression of Bax remained 
A

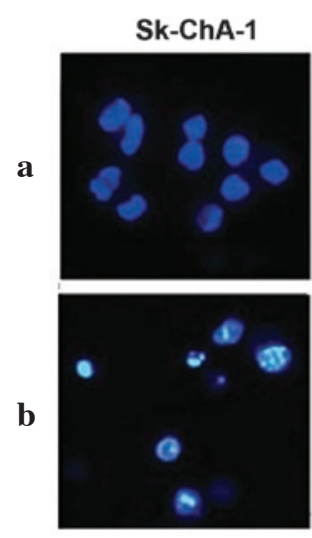

B

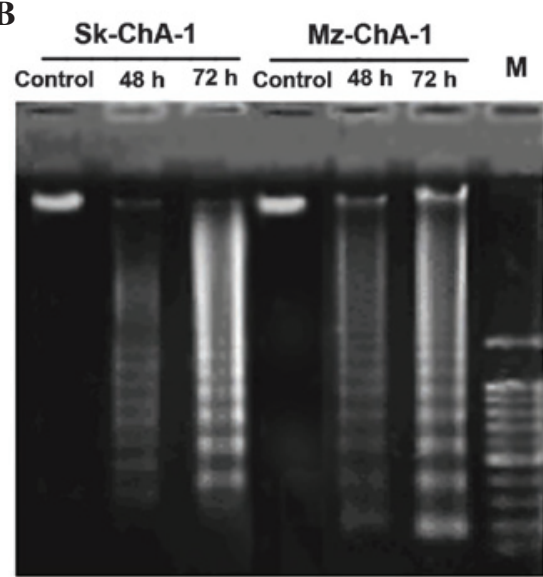

C

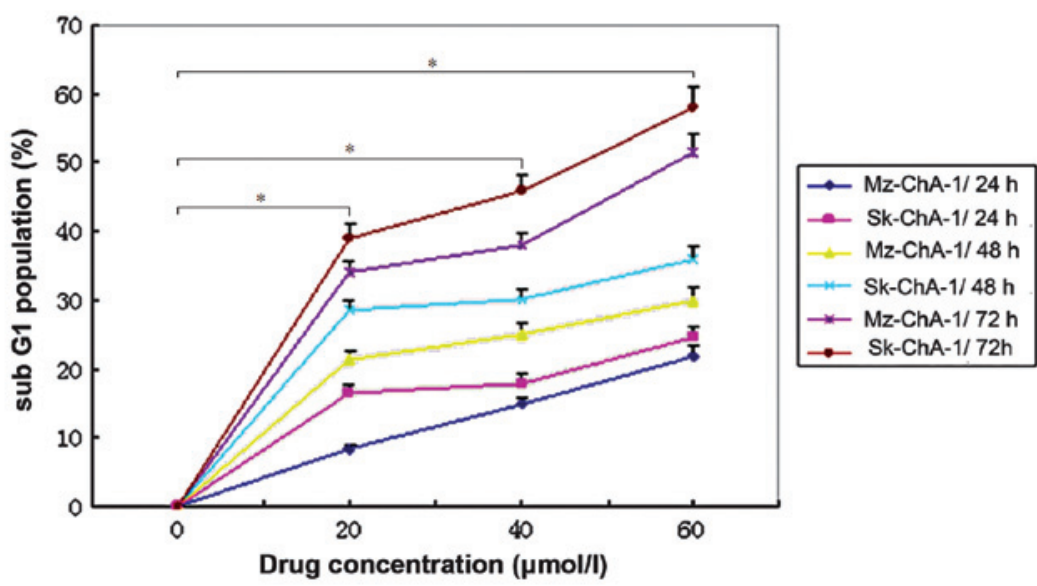

Figure 3. Cell apoptosis induced by guggulsterone. (A) Human cholangiocarcinoma cells were incubated in (a) medium alone for $72 \mathrm{~h}$ or (b) medium containing $60 \mu \mathrm{mol} / \mathrm{l} \mathrm{Z}$-guggulsterone for $72 \mathrm{~h}$. The viable cells possessed normal-shaped nuclei that were faintly stained with Hoechst 33258 . The apoptotic cells possessed shrunken nuclei with evidence of chromatin condensation. The results are representative of three replicate experiments (magnification, x200). (B) The human cholangiocarcinoma Sk-ChA-1 and Mz-ChA-1 cells were incubated in the medium in the absence or presence of $60 \mu \mathrm{mol} / \mathrm{l} \mathrm{Z}$-guggulsterone for the indicated times. A characteristic DNA ladder was clearly observed subsequent to the treatment of the cells (M, 100 bp DNA marker). (C) Following treatment of the Sk-ChA-1 and Mz-ChA-1 cells with various concentrations of Z-guggulsterone for 24, 48 and $72 \mathrm{~h}$, the apoptotic rate was detected. "P<0.001 vs. control. The data are expressed as the mean \pm standard deviation of three replicate experiments.

constant (Fig. 5), indicating the important roles of survivin and Bcl-2 during the apoptosis induced by guggulsterone.

\section{Discussion}

At present, anticancer drugs extracted from plants, such as Adriamycin (20), paclitaxel (21) and etoposide (22), are widely used in clinical settings. The identification of novel anti-cancer agents from natural plants is becoming a well-known strategy for studies (23).

In the present study, it was demonstrated that guggulsterone was able to inhibit the proliferation of the cholangiocarcinoma Sk-ChA-1 and Mz-ChA-1 cell lines, indicating that guggulsterone may be a good candidate for additional investigation as a chemotherapeutic agent for cholangiocarcinoma.

A panel of experiments was then performed to explore the underlying mechanisms of the effect of guggulsterone. Hoechst 33258 staining revealed that treatment with guggulsterone resulted in notable morphological indications of apoptosis, including the condensation of chromatin and nuclear fragmentation in cholangiocarcinoma Sk-ChA-1 and Mz-ChA-1 cells. In addition, typical DNA fragmentation, a hallmark of apoptosis, was also observed subsequent to the cells being treated with $60 \mu \mathrm{mol} / \mathrm{l} \mathrm{Z}$-guggulsterone for 48 and 72 h. Flow cytometry revealed that Z-guggulsterone induced apoptosis in cholangiocarcinoma Sk-ChA-1 and Mz-ChA-1 cells in a time- and dose-dependent manner. Consistently, the present findings were supported by previous studies that identified similar effects of guggulsterone in other types of cancer cells (13-16).

As previously reported, there are two major signaling pathways involved in apoptosis, the extrinsic death receptor pathway and intrinsic mitochondrial pathway (24-27). In the extrinsic pathway, caspase- 8 is first activated by the death-inducing signaling complex. The active form of caspase- 8 then activates downstream executioner caspases, including caspase-3, and also cleaves $\mathrm{BH} 3$ interacting domain death agonist (Bid) into truncated Bid, which eventually leads to the activation of the intrinsic pathway (28). In the intrinsic pathway, several apoptogenic molecules, including cytochrome $c$ and apoptosis-inducing factor, are released into the cytosol following the mitochondrial membrane permeability transition (25). Cytochrome $c$ then interacts with apoptotic protease-activating factor 1 and pro-caspase-9, and subsequently activates 

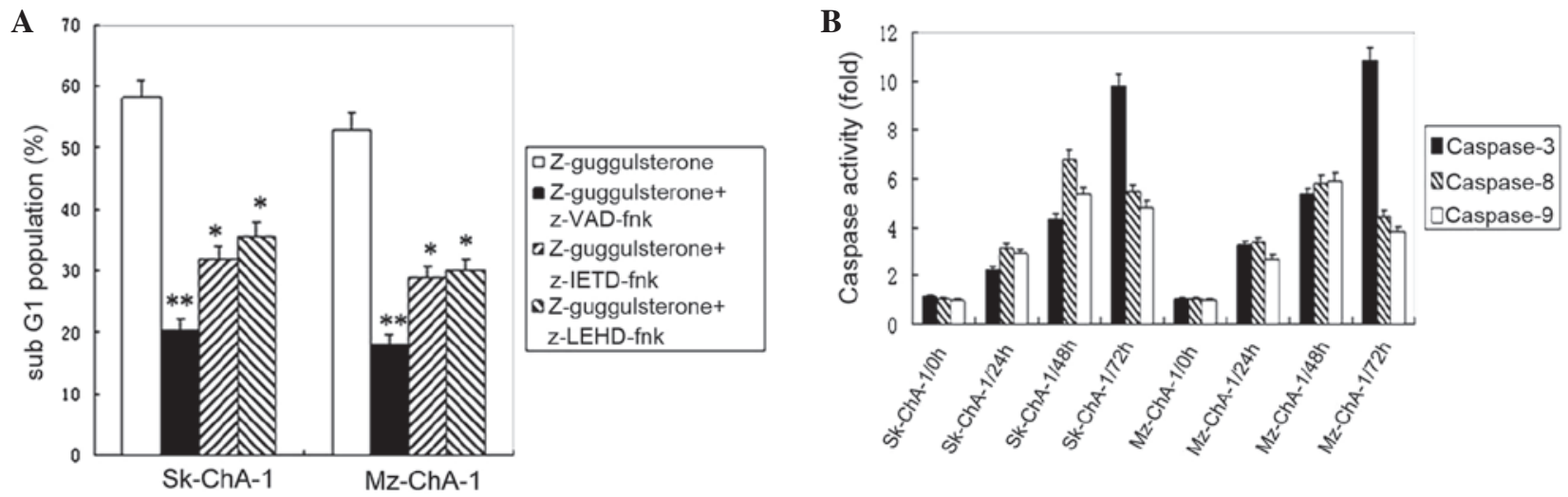

C a

Sk-ChA-1

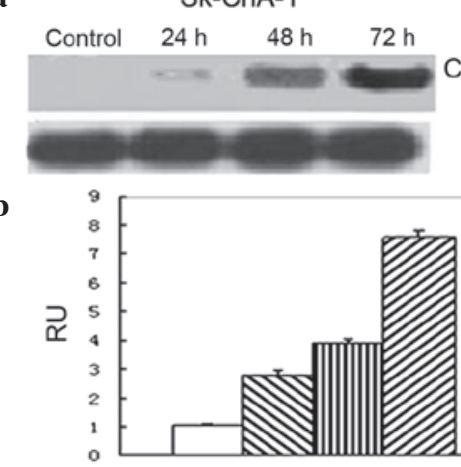

Sk-ChA-1

\section{$\mathrm{Mz}-\mathrm{ChA}-1$}

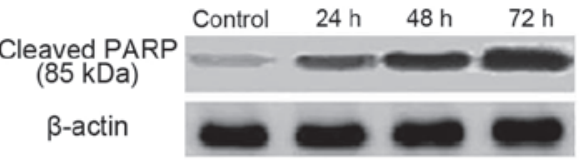

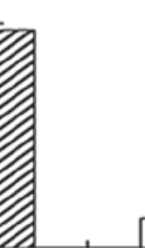

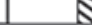

Figure 4. Caspases involved in guggulsterone-induced apoptosis. (A) Effect of caspase inhibitors on guggulsterone-induced apoptosis. The Sk-ChA-1 and Mz-ChA-1 cells were cultured in the absence or presence of $100 \mu \mathrm{M} \mathrm{z}$-VAD-fmk, z-LEHD-fmk or z-IETD-fmk for $2 \mathrm{~h}$ prior to the addition of $60 \mu \mathrm{mol} / \mathrm{l} \mathrm{Z}$-guggulsterone, and the cells were then incubated for $72 \mathrm{~h}$. The data are expressed as the mean $\pm \mathrm{SD}$ of three replicate experiments. ${ }^{*} \mathrm{P}<0.01$, ${ }^{* *} \mathrm{P}<0.001$ vs. Z-guggulsterone group. (B) Activity of caspase-3, -8 and -9 in guggulsterone-treated cholangiocarcinoma Sk-ChA-1 and Mz-ChA-1 cells.

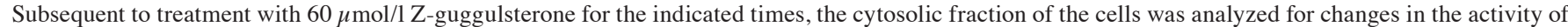
caspases-3, -8 and -9 using a colorimetric assay. The data are expressed as the mean \pm SD of three independent experiments. (C) Cleavage of PARP in guggulsterone treated cholangiocarcinoma Sk-ChA-1 and Mz-ChA-1 cells. The cells were treated with $60 \mu \mathrm{mol} / \mathrm{l}$ Z-guggulsterone for the indicated times, and then whole-cell underwent western blotting to assess the expression of the $85 \mathrm{kDa}$ cleaved PARP. $\beta$-actin was used as internal control to ensure that equal amounts of proteins were loaded into each lane. (a) The western blotting results are representative of three replicate experiments. (b) The densities of the cleaved PARP bands were determined and the relative quantity of the target protein was reported as RU. SD, standard deviation; PARP, poly (adenosine diphosphate-ribose) polymerase; RU, relative units.

A

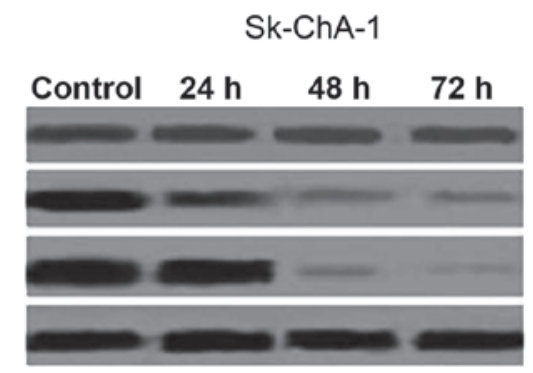

B

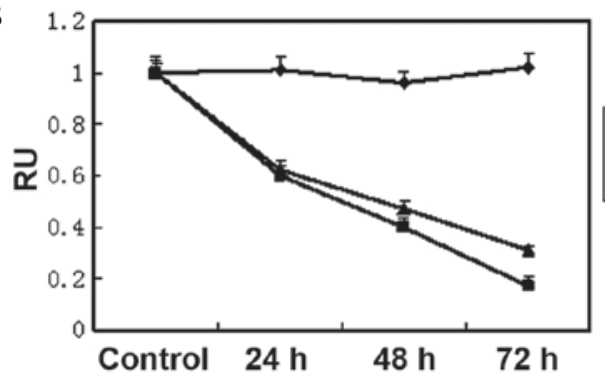

Mz-ChA-1
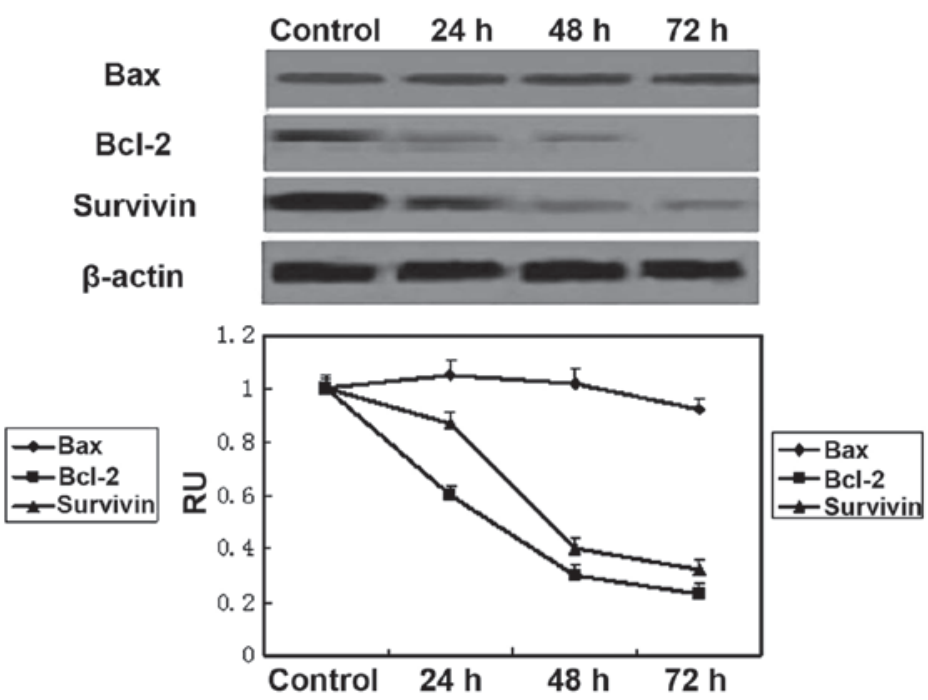

Figure 5. Effect of guggulsterone on the expression of apoptosis-associated genes. Subsequent to treatment with $60 \mu$ mol/1 Z-guggulsterone for 24,48 and $72 \mathrm{~h}$, the whole-cell lysates were subjected to western blotting to assess the expression of the survivin, Bcl- 2 and Bax proteins. $\beta$-actin was used as internal control to ensure that equal amounts of proteins were loaded into each lane. (A) The western blotting results are representative of three replicate experiments. (B) The densities of the protein bands was determined and the relative quantity of the target protein was reported as RU. Bcl-2, B-cell lymphoma 2; Bax, Bcl-2-associated X protein; RU, relative units. 
caspase-9 $(23,24)$. The active caspase-9 activates proteins, including pro-caspase- 3 and cleaved PARP, which initiates a cascade that finally leads to cellular apoptosis (27). In addition, there are also several other caspase-independent pathways (29). For example, apoptosis-inducing factor may translocate from the mitochondrial intermembrane to the nucleus and result in chromatin condensation and large-scale DNA fragmentation, leading to apoptotic cell death (30).

In addition, pre-treatment with the caspase inhibitors z-VAD-fmk, z-LEHD-fmk and z-IETD-fmk effectively impaired guggulsterone-induced apoptosis, indicating that caspase cascades play critical roles during the induction of apoptosis caused by guggulsterone. The colorimetric assay revealed that guggulsterone activated caspases-8, -9 and -3. As the main substrate of caspases, the alteration in the expression of cleaved PARP also supports this conclusion. Consistent with the present results, several other studies have reported that caspase-dependent apoptosis induced by guggulsterone also occurred in prostate and colon cancer cells $(13,16)$. Additional studies investigating the possibility that guggulsterone triggers apoptosis through caspase-independent pathways are required in the future, as the caspase inhibitors used in the present study did not completely abolish guggulsterone-induced apoptosis.

Survivin is a member of the inhibitor of apoptosis protein family and is usually overexpressed in human cancers (31). It has been found that cancer cells demonstrating overexpression of survivin are resistant to numerous apoptotic stimuli (32). By contrast, the downregulation of survivin causes spontaneous apoptosis or sensitizes cancer cells to these apoptotic stimuli (32-34). It has previously been reported that survivin is overexpressed in the majority of cholangiocarcinoma cells, which was closely associated with poor outcomes, indicating that survivin may be a promising target for the treatment of cholangiocarcinoma (35-37).

The Bcl-2 family, which consists of 20 homologues of apoptosis-inhibiting and apoptosis-promoting Bcl-2 proteins, plays key regulatory roles in mitochondria-mediated apoptosis (38). Bcl-2 and Bax are major apoptosis-inhibiting and -promoting proteins, respectively (39). It has previously been revealed that invalid therapeutic outcomes are mostly associated with the overexpression of apoptosis-inhibiting proteins, particularly Bcl-2, in numerous types of human cancer (40). By contrast, Bax has been revealed to constitute a requisite gateway to the mitochondria-dependent pathway of apoptosis (41). Therefore, upregulating the level of Bax may also improve the sensitivities to anti-cancer agents in these cancer cells (42). In addition, Bcl-2 and Bax may dimerize with each other and mutually neutralize their biological functions, resulting in the initiation of apoptosis (39). Thus, the Bcl-2/Bax ratio is an important index for the determination of cellular susceptibility to apoptosis (43).

The present study revealed that guggulsterone-induced apoptosis is accompanied by a reduction in the expression of survivin and Bcl-2. Despite survivin and Bcl-2 each acting as apoptosis inhibitors, these proteins execute biological functions through various pathways that regulate cellular apoptosis (44). Survivin may directly interact with and suppress the terminal effector cell-death proteases, such as caspase-3 and caspase-7 (40), while Bcl-2 mainly prevents the release of cytochrome $c$ and then blocks the progression of apoptosis (34). The present study identified that survivin and Bcl-2 were concurrently downregulated by guggulsterone, which was consistent with the findings of previous studies $(41,42)$.

In summary, the present study demonstrated that guggulsterone suppressed tumor proliferation by inducing cellular apoptosis in human cholangiocarcinoma cells. The current study also revealed that the apoptosis induced by guggulsterone was caspase-dependent and accompanied by the downregulation of survivin and Bcl-2. These findings indicate the therapeutic potential of guggulsterone in treating cholangiocarcinoma.

\section{Acknowledgements}

This study was supported by the Scientific Research Foundation of Anhui Medical University (grant no., 2012xkj049), Youth Talents Plan of the First Affiliated Hospital of Anhui Medical University (grant no., 2010KJ01) and Natural Science Foundation of Higher Education of Anhui Province (grant no., KJ2012A163).

\section{References}

1. Lazaridis $\mathrm{KN}$ and Gores GJ. Cholangiocarcinoma. Gastroenterology 128: 1655-1667, 2005.

2. West J, Wood H, Logan RF, Quinn M and Aithal GP: Trends in the incidence of primary liver and biliary tract cancers in England and Wales 1971-2001. Br J Cancer 94: 1751-1758, 2006.

3. Anderson CD, Pinson CW, Berlin J and Chari RS: Diagnosis and treatment of cholangiocarcinoma. Oncologist 9: 43-57, 2004.

4. Sirica AE: Cholangiocarcinoma: Molecular targeting strategies for chemoprevention and therapy. Hepatology 41: 5-15, 2005.

5. Fulda S, Gorman AM, Hori O and Samali A: Cellular stress responses: Cell survival and cell death. Int J Cell Biol 2010: 214074, 2010.

6. Fabregat I, Roncero C and Fernández M: Survival and apoptosis: A dysregulated balance in liver cancer. Liver Int 27: 155-162, 2007.

7. Ferreira CG, Epping M, Kruyt FA and Giaccone G: Apoptosis: Target of cancer therapy. Clin Cancer Res 8: 2024-2034, 2002.

8. Kim ND, Im E, Yoo YH and Choi YH: Modulation of the cell cycle and induction of apoptosis in human cancer cells by synthetic bile acids. Curr Cancer Drug Targets 6: 681-689, 2006.

9. Gujral ML, Sareen K, Tangri KK, Amma MK and Roy AK: Antiarthritic and anti-inflammatory activity of gum guggul (Balsamodendron mukul Hook). Indian J Physiol Pharmacol 4: 267-273, 1960.

10. Sharma JN and Sharma JN: Comparison of the anti-inflammatory activity of Commiphora mukul (an indigenous drug) with those of phenylbutazone and ibuprofen in experimental arthritis induced by mycobacterial adjuvant. Arzneimittelforschung 27: 1455-1457, 1977.

11. Urizar NL and Moore DD: GUGULIPID: A natural cholesterol-lowering agent. Annu Rev Nutr 23: 303-313, 2003.

12. Urizar NL, Liverman AB, Dodds DT, Silva FV, Ordentlich P, Yan Y, Gonzalez FJ, Heyman RA, Mangelsdorf DJ and Moore DD: A natural product that lowers cholesterol as an antagonist ligand for FXR. Science 296: 1703-1706, 2002.

13. Singh SV, Choi S, Zeng Y, Hahm ER and Xiao D: Guggulsterone-induced apoptosis in human prostate cancer cells is caused by reactive oxygen intermediate dependent activation of c-Jun $\mathrm{NH}_{2}$-terminal kinase. Cancer Res 67: 7439-7449, 2007.

14. Shishodia S, Sethi G, Ahn KS and Aggarwal BB: Guggulsterone inhibits tumor cell proliferation, induces S-phase arrest, and promotes apoptosis through activation of c-Jun N-terminal kinase, suppression of Akt pathway, and downregulation of antiapoptotic gene products. Biochem Pharmacol 74: 118-130, 2007.

15. Samudio I, Konopleva M, Safe S, McQueen T and Andreeff M: Guggulsterones induce apoptosis and differentiation in acute myeloid leukemia: Identification of isomer-specific antileukemic activities of the pregnadienedione structure. Mol Cancer Ther 4: 1982-1992, 2005.

16. An MJ, Cheon JH, Kim SW, Kim ES, Kim TI and Kim WH: Guggulsterone induces apoptosis in colon cancer cells and inhibits tumor growth in murine colorectal cancer xenografts. Cancer Letters 279: 93-100, 2009. 
17. Macha MA, Rachagani S, Gupta S, Pai P, Ponnusamy MP, Batra SK and Jain M: Guggulsterone decreases proliferation and metastatic behavior of pancreatic cancer cells by modulating JAK/STAT and Src/FAK signaling. Cancer Lett 341: 166-177, 2013.

18. Guan B, Li H, Yang Z, Hoque A and Xu X: Inhibition of farnesoid X receptor controls esophageal cancer cell growth in vitro and in nude mouse xenografts. Cancer 119: 1321-1329, 2013.

19. Herrmann M, Lorenz HM, Voll R, Grünke M, Woith W and Kalden JR. A rapid and simple method for the isolation of apoptotic DNA fragments. Nucleic Acids Res 22: 5506-5507, 1994.

20. Kanjeekal S, Chambers A, Fung MF and Verma S: Systemic therapy for advanced uterine sarcoma: A systematic review of the literature. Gynecol Oncol 97: 624-637, 2005.

21. Wiseman LR and Spencer CM: Paclitaxel. An update of its use in the treatment of metastatic breast cancer and ovarian and other gynaecological cancers. Drugs Aging 12: 305-334, 1998.

22. Jiang J, Liang X, Zhou X, Huang L, Huang R, Chu Z and Zhan Q: A meta-analysis of randomized controlled trials comparing irinotecan/platinum with etoposide/platinum in patients with previously untreated extensive-stage small cell lung cancer. J Thorac Oncol 5: 867-873, 2010.

23. Karikas GA: Anticancer and chemopreventing natural products: Some biochemical and therapeutic aspects. J BUON 15: 627-638, 2010.

24. Reed JC: Apoptosis-regulating proteins as targets for drug discovery. Trends Mol Med 7: 314-319, 2001.

25. Desagher S and Martinou JC: Mitochondria as the central control point of apoptosis. Trends Cell Biol 10: 369-377, 2000.

26. Van Loo G, Saelens X, Van Gurp M, MacFarlane M, Martin SJ and Vandenabeele P: The role of mitochondrial factors in apoptosis: A Russian roulette with more than one bullet. Cell Death Differ 9: 1031-1042, 2002.

27. Thornberry NA and Lazebnik Y: Caspases: Enemies within. Science 281: 1312-1316, 1998.

28. Fulda S: Targeting extrinsic apoptosis in cancer: Challenges and opportunities. Semin Cell Dev Biol 39: 20-25, 2015.

29. Liang Q, Li W and Zhou B: Caspase-independent apoptosis in yeast. Biochim Biophys Acta 1783: 1311-1319, 2008.

30. Susin SA, Lorenzo HK, Zamzami N, Marzo I, Snow BE, Brothers GM, Mangion J, Jacotot E, Costantini P, Loeffler M, et al: Molecular characterization of mitochondrial apoptosis-inducing factor. Nature 397: 441-446, 1999.

31. Li F: Survivin study: What is the next wave? J Cell Physiol 197: 8-29, 2003.

32. Li F, Ambrosini G, Chu EY, Plescia J, Tognin S, Marchisio PC and Altieri DC: Control of apoptosis and mitotic spindle checkpoint by survivin. Nature 396: 580-584, 1998.
33. Mirza A, McGuirk M, Hockenberry TN, Wu Q, Ashar H, Black S, Wen SF, Wang L, Kirschmeier P, Bishop WR, et al: Human survivin is negatively regulated by wild-type p53 and participates in p53-dependent apoptotic pathway. Oncogene 21: 2613-2622, 2002.

34. Beltrami E, Plescia J, Wilkinson JC, Duckett CS and Altieri DC: Acute ablation of survivin uncovers p53-dependent mitotic checkpoint functions and control of mitochondrial apoptosis. J Biol Chem 279: 2077-2084, 2004.

35. Chang Q, Liu ZR, Wang DY, Kumar M, Chen YB and Qin RY: Survivin expression induced by doxorubicin in cholangiocarcinoma. World J Gastroenterol 10: 415-418, 2004.

36. Javle MM, Tan D, Yu J, LeVea CM, Li F, Kuvshinoff BW and Gibbs JF: Nuclear survivin expression predicts poor outcome in cholangiocarcinoma. Hepatogastroenterol 51: 1653-1657, 2004.

37. Obama K, Ura K, Li M, Katagiri T, Tsunoda T, Nomura A, Satoh S, Nakamura Y and Furukawa Y: Genome-wide analysis of gene expression in human intrahepatic cholangiocarcinoma. Hepatology 41: 1339-1348, 2005.

38. Antonsson B: Mitochondria and the Bcl-2 family proteins in apoptosis signaling pathways. Mol Cell Biochem 256-257: $141-155,2004$.

39. Nascimento Pde S, Ornellas AA, Campos MM, Scheiner MA, Fiedler W and Alves G: Bax and bcl-2 imbalance and HPB infection in penile tumors and adjacent tissues. Prog Urol 14: 353-359, 2004 (In French).

40. Reed JC. Double identity for proteins of the Bcl-2 family. Nature 387: 773-776, 1997.

41. Wei MC, Zong WX, Cheng EH, Lindsten T, Panoutsakopoulou V, Ross AJ, MacGregor GR, Thompson CB and Korsmeyer SJ: Proapoptotic BAX and BAK: A requisite gateway to mitochondrial dysfunction and death. Science 292: 727-730, 2001.

42. Zhang CL, Wu LJ, Tashiro S, Onodera S and Ikejima T: Oridonin induces apoptosis of HeLa cells via altering expression of $\mathrm{Bcl}-2 / \mathrm{Bax}$ and activating caspase-3/ICAD pathway. Acta Pharmacol Sin 25: 691-698, 2004.

43. Manion MK and Hockenbery DM: Targeting BCL-2-related proteins in cancer therapy. Cancer Biol Ther 2 (Suppl 1): S105-S114, 2003

44. Kanwar JR, Kamalapuram SK and Kanwar RK: Targeting survivin in cancer: The cell-signalling perspective. Drug Discov Today 16: 485-494, 2011. 